\title{
Correlation of Centromeric Heterochromatin C-band Polymorphism with Breeding Failure in Mice
}

\author{
Marcin MARCINIAK, Malgorzata LENARTOwICZ, Aniela GOLAS, and Jozefa STYRNA
}

Accepted Maj 25, 2010

\begin{abstract}
MARCiniak M., LenARTOWiCZ M., GOlAS A., STYRna J. 2010. Correlation of centromeric heterochromatin C-band polymorphism with breeding failure in mice. Folia biol. (Kraków) 58: 251-255.

The aim of the present study was to test the hypothesis about the relation between segregation of chromosomes 14 and 18 and the deterioration of mouse fertility and vitality. The analysis was possible because $\mathrm{C}$-banding on chromosome 14 and chromosome 18 of the CBA/Kw and $\mathrm{KE}$ strains show size polymorphism. A small sized C-band on chromosome 14 is characteristic for the CBA/Kw mice, while the KE mice show small C-bands on chromosomes 18 . Thus, if fertility parameters are affected in a centromere-dependent manner, we should observe non-random inheritance of both chromosome pairs in recombinant inbred (RI) strains. The results showed statistically significant preferential segregation of chromosomes 14 and 18 with small C-bands. Most of the RI strains inherited chromosome 14 from the CBA/Kw strain and chromosome 18 from the KE strain, and did not manifest a deterioration of fertility and vitality. On the contrary, RI strains that inherited chromosomes 14 and 18 from one of the parental strains, particularly the KE strain, stopped breeding or had difficulties in producing the next generation.

Key words: Recombinant inbred strain, chromosome segregation, C-band staining.

Marcin MARCINIAK, Malgorzata LENARTOWICZ, Aniela GOLAS, Jozefa STYRNA, Department of Genetics and Evolution, Institute of Zoology, Jagiellonian University, Ingardena 6, 30-060 Kraków, Poland.

E-mail:marcin.marciniak@uj.edu.pl malgorzata.lenartowicz@gmail.com aniela.golas@uj.edu.pl styr@zuk.iz.uj.edu.pl
\end{abstract}

In eukaryotic chromosomes the centromere is the region that is responsible for proper segregation during cell division. The centromeric region contains a kinetochore, a massive multi-protein complex that provides the single side for spindle microtubule attachments. A defect in centromere function results in aneuploidy and chromosome instability which leads to cancer or birth defects (DALAL 2009; PEZER \& UGARKOVIC 2008).

The centromeric region is embedded in pericentromeric heterochromatin. In contrast to euchromatin, heterochromatin is a more condensed, gene poor region that contains highly repetitive DNA sequences (PEZER \& UGARKOVIC 2008; UGARKOVIC \& PLOHL 2002). Heterochromatin regions were recognized as less active, however, recent investigations have indicated that heterochromatin plays an important role in genome stability, chromosomal segregation and gene expression regulation (EYMERY et al. 2009; GIENI et al. 2008; PEZER \& UGARKOVIC 2008).

In the interphase nucleus centromeric heterochromatin is seen as a normal DAPI-bright region, but in metaphase chromosomes the centromere is cytologically distinct from the rest of the chromosomes (PINDOUX \& ALLSHIRE 2005) and can be visualized as a darkly stained $\mathrm{C}$-band region (DAVISSON 1981). In humans and in mice $C$-bands consist mainly of highly repetitive satellite DNA. In humans and many species of animals, including Mus musculus, C-band polymorphism was described as the size difference between autosomes (MODI 1993; IMAI 1991; YOSHIDA \& KODAMA 1983; YASSEEN \& AL-KHAFAJI 2002). Moreover, these differences were described between inbred strains of laboratory mice and serve as a chromosome marker useful for strain identification. Each inbred mouse strain was found to have a characteristic C-banding pattern (DAVISSON 1981; YOSHIDA \& KODAMA 1983), possessing large, normal and small centromeric heterochomatin on different chromosomes (DAVISSON 1981).

There is some data indicating that in humans Cband polymorphism is associated with male infertility (YASSEEN \& AL-KHAFAJI 2002; YAKIN et 
al. 2005; MINOCHERHOMJI et al. 2009; DE LA FUENTE-CORTES et al. 2009). In the Department of Genetics and Evolution an intensive study on fertility and gamete quality in mice has been performed. Mice from recombinant inbred (RI) strains were used. Our RI strains were derived from two parental laboratory inbred strains (KE and $\mathrm{CBA} / \mathrm{Kw}$ ) that differ in several features associated with fertility: proportion of abnormal sperm, timing of meiotic maturation of oocytes, solubility of oocyte investment and percentage of in vivo fertilization (KRZANOWSKA et al. 1995; WABIK-SLIZ et al. 2005; GOLAS et al. 2008). RI strains are the source of homozygous and repeatable combinations of alleles that were distinct in the progenitor strain. Therefore they are useful for gene mapping, the analysis of pleiotropism and for studies of genetic and physiological correlations between characters.

Using C-band staining analysis we revealed that the $\mathrm{C}$-band on chromosomes 14 of the $\mathrm{CBA} / \mathrm{Kw}$ strain and that of chromosome 18 of the KE strain show size polymorphism: while the $\mathrm{CBA} / \mathrm{Kw}$ mice have a small sized C-band on chromosome 14, the KE mice show small C-bands on chromosome 18 . During the last two decades we have started inbreeding 74 lines of inbred strains but many of them died due to fertility problems. Preferential segregation of chromosomes with a small variant of centromere chromatin was noted (LENARTOWICZ \& WOJCIK 1999). In this study we analyzed the C-band staining pattern in newly obtained RI strains at the beginning of the inbreeding procedure. At this stage most recombinant strains die due to inbreeding depression, including the adverse effect of genes combinations. This experiment would reveal whether chromosome polymorphism correlates with breeding failure.

\section{Material and Methods}

All the animals were bred at the Department of Genetics and Evolution, Jagiellonian University, Kraków. Thirty-one recombinant inbred (RI) strains were obtained. RI strains $10,40,41,42,43,44,47$, 49,51 and 52 were derived from crossing a $\mathrm{KE}$ female with $\mathrm{CBA} / \mathrm{Kw}$ (referred to as $\mathrm{CBA}$ ) males. RI strains $13,17,20,26,27,28,29,32,33,34,60,62$, $63,65,67,69,70,71,72,74$ and 75 resulted from crossing KE males with CBA females. At least 3 animals from each RI strain were analyzed.

Separate RI strains were not obtained at the same time, therefore the analyzed individuals originated from different generations. From the oldest strains (RI from 10 to 52) individuals more advanced than the F20 generation were used. The remaining RI strains (RI 60 to 75 ) were analyzed at the early
F5-F7 generation. Most of them stopped breeding soon after analysis, possibly because of inbreeding depression. This phenomenon is strongly manifested in F2-F8 generations in various components of fertility (STRONG 1978).

The animals were killed by cervical dislocation and metaphase plates were prepared from the bone marrow cells according to NOMURA et al. (1984). C-banding was performed by standard barium hydroxide, trypsin and Giemsa methods (SUMMER 1972). At least four metaphase plates from one mouse were analyzed by LM (100x). Additionally, analysis of microsatellite polymorphic loci close to the centromeric region of 14 and 18 chromosome (namely D14Mit78 and D18Mit110, respectively) was also applied. Microsatellite markers were tested in RI 17, 29, 40, 41, 42, 43, 44, 47, 49, $60,63,65,67,70,72,74$ and 75 strains (as other strains were no longer alive).

\section{Results}

Only complete metaphase plates containing 40 chromosomes were analyzed. The analysis revealed that the $\mathrm{C}$-bands on chromosomes 14 and 18 of the CBA and KE strains show size polymorphism: the CBA mice have a small sized C-band on chromosome 14 (Fig. 1), while the KE mice show small C-bands on chromosome 18 (Fig. 2).

Non-random inheritance of 14 and 18 chromosomes was noted in RI strains that passed generation F20 (Table 1). Most of the RI strains possessed chromosome 14 with a small C-band (CBA shape). Chromosome 14 with a normal C-band (KE shape) was detected only in 3 of 20 RI strains, i.e. RI 27, 47 and 49. On the contrary, only two RI strains (RI 10 and 43) inherited chromosomes 18 with large heterochromatin, typical of the CBA parental strain. Both chromosome pairs were inherited from the KE strain in 3 of $20 \mathrm{RI}$ strains. Two RI strains derived both chromosomes from the CBA parental strain.

In newly developed RI strains (RI 60 to 75; Table 2), heterozygosity was still observed when chromosome 18 was analyzed: one chromosome of pair 18 was KE shaped while the second one was CBA shaped (Fig. 3). Surprisingly, none of the youngest RI strains inherited the large C-chromatin in both chromosomes 14 and 18; however, in the RI 70 strain KE shaped chromosomes 14 and heterozygous chromosomes 18 are present (Fig. 3).

Statistical analysis using the chi square test showed that the preferential segregation of chromosomes with small C-chromatin was statistically significant in RI 10 to 52 as well as in RI 10 to 75 (chromosome 14: $\mathrm{P}<0.01$; chromosome 18: $\mathrm{P}<0.001$ ). 


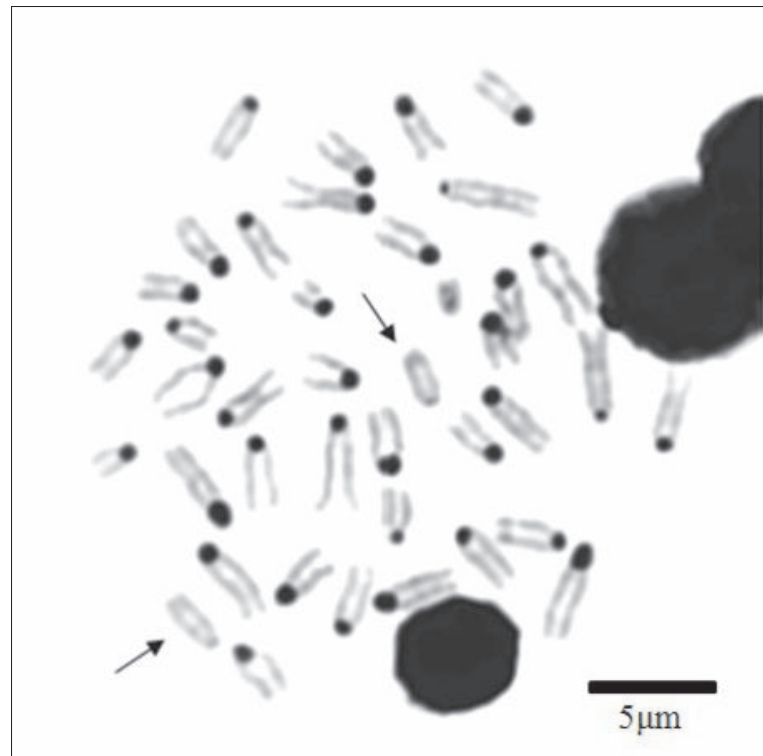

Fig. 1. Chromosome plate typical of CBA. Arrows point to chromosomes 14 with small C-band.

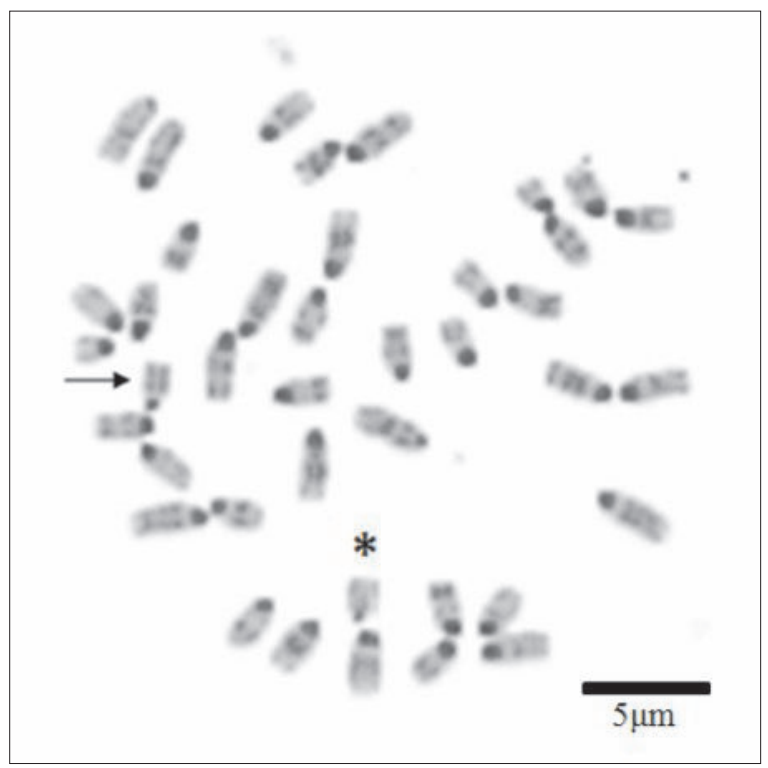

Fig. 3. Chromosome plate typical of RI 70. Arrow points to chromosome 18 with normal C-band, star points to chromosome 18 with small C-band.

The analysis of microsatellite loci confirmed Cbanding staining in all $17 \mathrm{RI}$ strains except for two. In RI 41, possessing chromosome 14 after the CBA parental strain, microsatellite marker (D14Mit78, $3 \mathrm{cM}$ ) was inherited from the KE strain. In strain 72 RI chromosome 18 was after CBA strain, but microsatellite marker (D18Mit110, 4cM) was derived from the KE strain. In both cases the recombination fraction was $5.9 \%$, which is close to the database location of these markers.

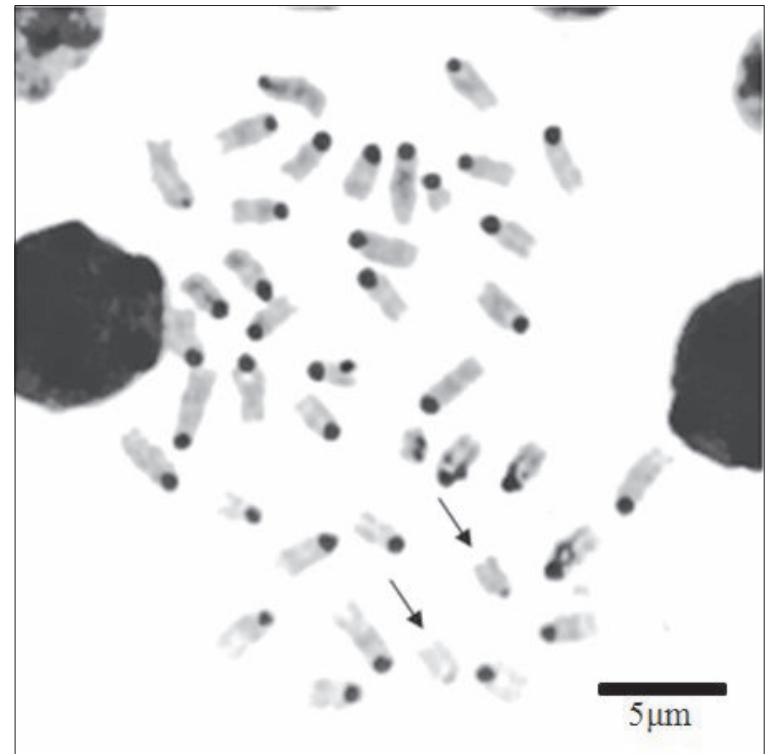

Fig. 2. Chromosome plate typical of KE. Arrows point to chromosomes 18 with small C-band.

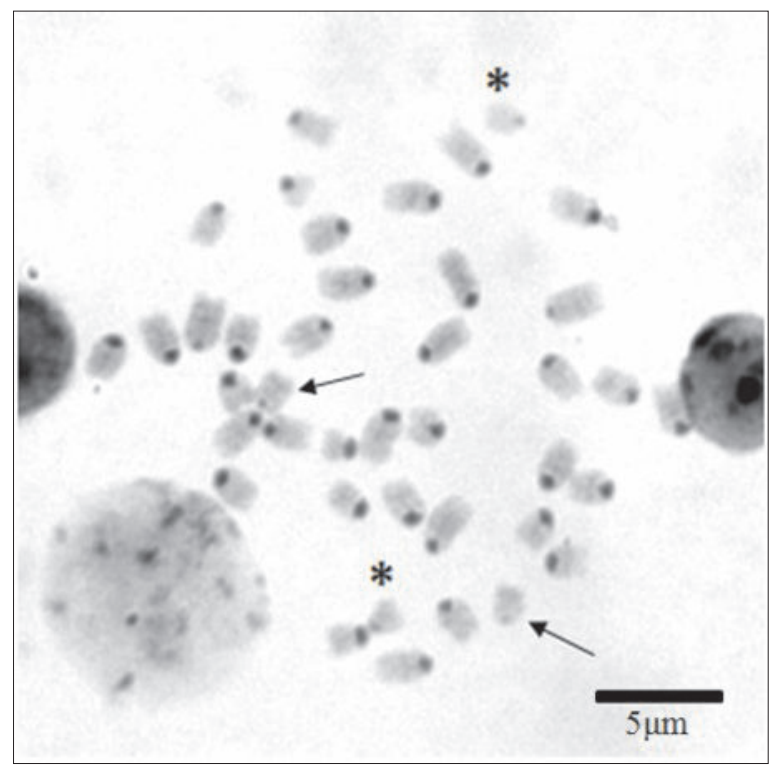

Fig. 4. Chromosome plate typical of RI 40. Arrows point to chromosomes 14 with small C-band, stars point to chromosomes 18 with also small C-band.

The results show that most RI strains that reached the inbred status (at least F20 generation) inherited chromosome 14 from the CBA strain and chromosome 18 from the KE strain (Fig. 4). On the contrary, the combination of chromosome 14 after KE and 18 after CBA strain seems to be segregated against, as only one RI strain (i.e. RI 70) can potentially establish this genotype. RI strains that possessed chromosomes 14 and 18 from the KE strain stopped breeding or had difficulties with producing the next generation. 
Table 1

The origin of chromosomes 14 and 18 in 20 recombinant inbred (RI) strains identified by $\mathrm{C}$-banding that exceeded generation F20

\begin{tabular}{||c|c|c||}
\hline RI strain & $\begin{array}{c}\text { Origin of 14 } \\
\text { chromosome }\end{array}$ & $\begin{array}{c}\text { Origin of 18 } \\
\text { chromosome }\end{array}$ \\
\hline \hline 10 & CBA & CBA \\
\hline 13 & CBA & KE \\
\hline 17 & CBA & KE \\
\hline 20 & CBA & KE \\
\hline 26 & CBA & KE \\
\hline 27 & KE & KE \\
\hline 28 & CBA & KE \\
\hline 29 & $\mathrm{CBA}$ & KE \\
\hline 32 & $\mathrm{CBA}$ & KE \\
\hline 33 & $\mathrm{CBA}$ & $\mathrm{KE}$ \\
\hline 34 & $\mathrm{CBA}$ & $\mathrm{KE}$ \\
\hline 40 & $\mathrm{CBA}$ & $\mathrm{KE}$ \\
\hline 41 & $\mathrm{CBA}$ & $\mathrm{KE}$ \\
\hline 42 & $\mathrm{CBA}$ & $\mathrm{KE}$ \\
\hline 43 & $\mathrm{CBA}$ & $\mathrm{CBA}$ \\
\hline 44 & $\mathrm{CBA}$ & $\mathrm{KE}$ \\
\hline 47 & $\mathrm{KE}$ & $\mathrm{KE}$ \\
\hline 49 & $\mathrm{KE}$ & $\mathrm{KE}$ \\
\hline 51 & $\mathrm{CBA}$ & $\mathrm{KE}$ \\
\hline 52 & $\mathrm{CBA}$ & $\mathrm{KE}$ \\
\hline & & \\
\hline \hline
\end{tabular}

\section{Discussion}

Heterochromatin polymorphism has been regarded for a long time as normal with no significant clinical function since this chromatin fraction is considered as a genomic wasteland. However, according to the newest report, this component of chromosome structure may be biologically important. Coding potential is limited not only to the nucleolar organizing regions but also involves centromeric and pericentromeric chromatin. Such transcripts seem to play a role in the cellular response to stress, cell development and differentiation as well as cell cycle (EYMERY et al. 2009). Moreover, it was postulated that special modification of heterochromatin in the pericentromeric region may maintain centromere size and creates a barrier against expansion of centromeric chromatin along the chromosome (SULLIVAN \& KARPEN 2004; MAGGERT \& KARPEN 2001).

Heterochromatin polymorphism has elevated frequency in infertile couples and in those with repeated
Table 2

The origin of chromosomes 14 and 18 in 11 newly obtained recombinant inbred (RI) strains between generations F5 and F7, identified by Cbanding. Strains that are no longer alive are underlined and in bold

\begin{tabular}{|c|c|c|}
\hline RI strain & $\begin{array}{c}\text { Origin of 14 } \\
\text { chromosome }\end{array}$ & $\begin{array}{c}\text { Origin of 18 } \\
\text { chromosome }\end{array}$ \\
\hline \hline$\underline{\mathbf{6 0}}$ & $\underline{\mathbf{C B A}}$ & $\underline{\mathbf{C B A}-K E}$ \\
\hline 62 & CBA & KE \\
\hline$\underline{\mathbf{6 3}}$ & $\underline{\mathbf{C B A}}$ & $\underline{\mathbf{C B A}-\mathrm{KE}}$ \\
\hline$\underline{\mathbf{6 5}}$ & $\underline{\mathbf{K E}}$ & $\underline{\mathbf{K E}}$ \\
\hline$\underline{\mathbf{6 7}}$ & $\underline{\mathbf{K E}}$ & $\underline{\mathbf{K E}}$ \\
\hline 69 & CBA & KE \\
\hline$\underline{\mathbf{7 0}}$ & $\underline{\mathbf{K E}}$ & $\underline{\mathbf{C B A}-K E}$ \\
\hline 71 & CBA & KE \\
\hline$\underline{\mathbf{7 2}}$ & $\underline{\mathbf{C B A}}$ & $\underline{\mathbf{C B A}}$ \\
\hline$\underline{\mathbf{7 4}}$ & $\underline{\mathbf{K E}}$ & $\underline{\mathbf{K E}}$ \\
\hline$\underline{\mathbf{5}}$ & $\underline{\mathbf{K E}}$ & $\underline{\mathbf{K E}}$ \\
\hline
\end{tabular}

miscarriages. Heterochromatin polymorphism was noted in women with primary infertility and in oligo- and azoospermic men with polymorphic variants in constitutive heterochromatin of the st, 9th and 16th chromosomes (YASSEEN \& AL-KHAFAJI 2002; YAKIN et al. 2005; MINOCHERHOMJI et al. 2008; DE LA FUENTE-CORTES et al. 2009). The results presented here confirm the involvement of centromere chromatin variants in fertility. The majority of RI strains that reached the inbred status (RI 10 to RI 52, Table 1) inherited chromosomes 14 and 18 with small C-bands, in accordance with data obtained previously (LENARTOWICZ \& WOJCIK 1999). This preferentially inherited genotype occurred only among those of the youngest strains (F5-F7 generation) that revealed no fertility disorders (RI 62, 69 and 71, Table 2). Other combinations of chromosomes 14 and 18, i.e. both chromosome pairs from one parental strain, seem to be segregated against at the very beginning of the breeding protocol. However, why do KE and CBA strains exist? We postulate that in the parental strains, as well as in RI 27, 47, 49 (chromosomes 14 and 18 from KE) and RI 43 (both chromosomes from CBA), not only centromere chromatin size plays role in fertility, but also the genetic background of the analyzed mice.

A probable explanation of the observed chromosome segregation results from the nature of large C-chromatin. BOUZINBA-SEGARD et al. (2006) proved that forced accumulation of specific murine minor satellite transcripts leads to defects in chromosome segregation and sister-chromatid 
cohesion. Since chromosomes with large Cchromatin transcribe more copies of centromeric RNA than those with small C-bands, this could explain possible meiotic disorders leading to aberrant reproductive cell production and consequently to infertility. This would explain the complete absence of the RI strain with both pairs of analyzed chromosomes with large $\mathrm{C}$-chromatin and the decreased number of strains with both chromosomes 14 and 18 from one of the progenitor strains (Tables $1 \& 2$ ). In case of RI 60, 63 and 70 strains, in which a heterozygous state of chromosome 18 pairs was noted, infertility could be a consequence of erroneous crossing-over. In summary, we propose a centromere-dependent fertility control mechanism through skewed segregation of chromosomes 14 and 18 in mice.

\section{References}

Bouzinba-Segard H., Guais A., Francastel C. 2006. Accumulation of small murine minor satellite transcripts leads to impaired centromeric architecture and function. Proc. Natl. Acad. Sci. U.S.A. 103: 8709-8714.

DALAL Y. 1981. Epigenetic speciation of centromeres. Biochem. Cell Biol. 87: 273-282.

DAVISSON M. T. 1981. Centromeric heterochromatine variants. (In: Genetics variants and strains of the laboratory mouse. M. C. Green ed. Fisher, Suttgart and New York): 357-358.

DE la Fuente-Cortes B. E., CERDA-Flores R. M., DAVILA-RODRIGUEZ M. I., GARCIA-VIELMA C., DE LA ROSA Alvarado R. M. CORTES-GutierReZ E. I. 2009. Chromosomal abnormalities and polymorphic variants in couples with repeated miscarriage in Mexico. Reprod. Biomed Online 18: 543-548.

EYMERY A., CALLANAN M., VOURC'H C. 2009. The secret message of heterochromatin: new insights into the mechanism and function of centromeric and pericentric repeat sequences transcription. Int. J. Dev. Biol. 53: 259-268.

GIENI R. S., CHAN G. K. T., HANDZEL M. J. 2008. Epigenetic regulate centromere formation and kinetochore function. $\mathrm{J}$. Cell Biochem. 104: 2027-2039.

Golas A., DzieZa A., KuZNiarZ K., StYrna J. 2008. Gene mapping of sperm quality parameters in recombinant inbred strains of mice. Int. J. Dev. Biol. 52: 287-293.

IMAI H. T. 1991. Mutability of constitutive heterochromatin (C-bands) during eukaryotic chromosomal evolution and their cytological meaning. Jpn. J. Genet. 66: 635-661.
KRZANOWSKa H., STYRna J., WABIK-SLIZ B. 1995. Analysis of sperm quality in recombinant inbred mouse strains: correlation of sperm head shape with sperm abnormalities and with the incidence of supplementary spermatozoa in the perivitelline space. J. Reprod. Fert. 104: 347-354.

LENARTOWICZ M., WOJCIK A. 1999. Preferential segregation of marker chromosomes 14 and 18 in mouse recombinant inbred strains derived from the $\mathrm{KE}$ and $\mathrm{CBA} / \mathrm{Kw}$ strains. Folia biol. (Kraków) 47: 131-134.

MAGGERT K. A., KARPEN G. H. 2001. The activation of neocentromere in Drosophila requires proximity to an endogenous centromere. Genetics 158: 1615-1628.

Minocherhom.t S., Athalye A. S., Madon P. F., KulKARNI D., UtTAMChadani S. A., PARIKH F. R. 2009. A case-control study identifying chromosomal polymorphic variations as forms of epigenetic alterations associated with the infertility phenotype. Fertil. Steril. 92: 88-95.

MODI W. S. 1993. Comparative analyses of heterochromatin in Microtus: sequence heterogeneity and localized expansion and contraction of satellite DNA arrays. Cytogenet. Cell Genet 62: 142-148.

NOMURA T., EsAKi K., TOMito T. 1984. Manual for genetic monitoring of inbred mice. University of Tokyo Press., pp. $150-152$.

PEZER Z., UGARKOVIC D. 2008. Role of non-coding RNA and heterochromatin in aneuploidy and cancer. Seminar in Cancer Biology 18: 123-130.

PINDOUX A. L, AlLSHIRE R. C. The role of heterochromatin in centromere function. Phil. Trans. R. Soc. 360: 569-579.

STRONG L. C. 1978. Inbred mice in science. (In: Origins of inbred mice. H. C. Morse ed. Academic Press, New York): 45-67.

Sullivan B. A., KARPEN G. H. 2004. Centromeric chromatin exhibits a histone modification pattern that is distinct from both euchromatin and heterochromatin. Nat. Struct. Mol. Biol. 11: 1076-1083.

SUMMER A. 1972. A simple metod for demonstrating centromeric heterochromatin. Exp. Cell Res. 75: 304-306.

UGARKOVIC D., PlOHL M. 2002. Variation in satellite DNA profiles-causes and effects. EMBO J. 21: 5955-5959.

WABIK-SLIZ B., GOŁAS A., KRZANOWSKA H. 2005. Analysis of oocyte quality in recombinant inbred mouse strains developed from KE and CBA strains that differ in fertilization efficiency. J. Appl. Genet. 46: 163-170.

YAKIN K., BALABAN B., URMAN B. 2005. Is there a possible correlation between chromosomal variants and spermatogenesis. Int. J. Urol. 12: 984-989.

YASSEN A. A., AL-KHAFAJI S. M. 2002. The significance of autosomal C-bands size polymorphism in male infertility. Saudi. Med. J. 23: 1473-1477.

YoshidA M. C., KodAMA Y. 1983. C-band patterns of chromosomes in 17 strains of mice. Cytogenet. Cell Genet. 35: $51-56$. 